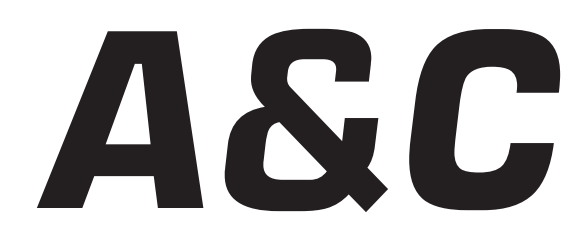

Revista de Direito Administrativo \& Constitucional

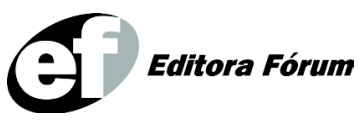

A\&C R. de Dir. Administrativo e Constitucional, Belo Horizonte, ano 6, n. 24, p. 1-246, abr.jun. 2006 


\section{A\&C REVISTA DE DIREITO ADMINISTRATIVO E CONSTITUCIONAL}

\section{IPDA}

Instituto Paranaense

de Direito Administrativo

Direção Geral

Romeu Felipe Bacellar Filho

Direção Editorial

Paulo Roberto Ferreira Motta

Direção Executiva

Emerson Gabardo

Conselho de Redação

Edgar Chiuratto Guimarães

Adriana da Costa Ricardo Schier

Célio Heitor Guimarães

Conselho Editorial

Adilson Abreu Dallari

Alice Gonzáles Borges

Carlos Ari Sundfeld

Carlos Ayres Britto

Carlos Delpiazzo

Cármen Lúcia Antunes Rocha

Celso Antônio Bandeira de Mello

Clèmerson Merlin Clève

Clóvis Beznos

Enrique Silva Cimma

Eros Roberto Grau

Fabrício Motta

Guilhermo Andrés Muñoz (in memoriam)

Jaime Rodríguez-Arana Muñoz

Jorge Luís Salomoni
José Carlos Abraão

José Eduardo Martins Cardoso

José Luís Said

José Mario Serrate Paz

Juan Pablo Cajarville Peruffo

Juarez Freitas

Julio Rodolfo Comadira

Luís Enrique Chase Plate

Lúcia Valle Figueiredo

Manoel de Oliveira Franco Sobrinho

(in memoriam)

Marçal Justen Filho

Marcelo Figueiredo

Márcio Cammarosano

Maria Cristina Cesar de Oliveira
Nelson Figueiredo

Odilon Borges Junior

Pascual Caiella

Paulo Eduardo Garrido Modesto

Paulo Henrique Blasi

Paulo Neves de Carvalho (in memoriam)

Paulo Ricardo Schier

Pedro Paulo de Almeida Dutra

Regina Maria Macedo Nery Ferrari

Rogério Gesta Leal

Rolando Pantoja Bauzá

Sérgio Ferraz

Valmir Pontes Filho

Yara Stropa

Weida Zancaner

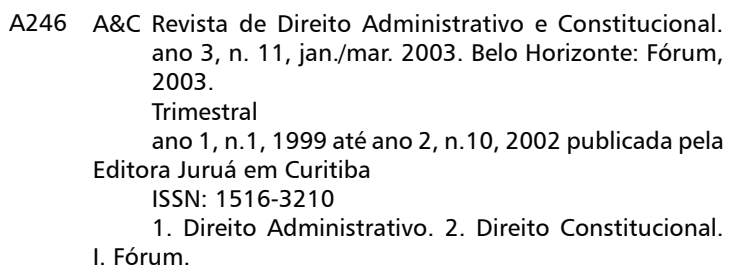

A246 A\&C Revista de Direito Administrativo e Constitucional. ano 3, n. 11, jan./mar. 2003. Belo Horizonte: Fórum, 2003.

Trimestral

ano 1, n.1, 1999 até ano 2, n.10, 2002 publicada pela Editora Juruá em Curitiba

ISSN: 1516-3210

1. Direito Administrativo. 2. Direito Constitucional. I. Fórum.

CDD: 342 CDU: 33.342

(c) Editora Fórum Ltda. 2006

Todos os direitos reservados. É proibida a reprodução total ou parcial, de qualquer forma ou por qualquer meio eletrônico ou mecânico, inclusive através de processos xerográficos, de fotocópias ou de gravação, sem permissão por escrito do possuidor dos direitos de cópias (Lei nº 9.610, de 19.02.1998).

\section{Editora Fórum Ltda}

Av. Afonso Pena, 2770 - 15\%16ªndar - Funcionários

CEP 30130-007 - Belo Horizonte/MG - Brasil

Tel.: 08007043737

Internet: www.editoraforum.com.br

e-mail: editoraforum@editoraforum.com.br
Editor responsável: Luís Cláudio Rodrigues Ferreira Projeto gráfico e diagramação: Luis Alberto Pimenta Revisora: Olga M. A. Sousa

Pesquisa jurídica: Fátima Ribeiro - OAB/MG 74868

Bibliotecária: Alessandra Rodrigues da Silva CRB 2778/MG 6a Região

Os conceitos e opiniões expressas nos trabalhos assinados são de responsabilidade exclusiva de seus autores.

Impressa no Brasil / Printed in Brazil

Distribuída em todo Território Nacional 


\title{
Por um conceito contemporâneo de democracia
}

\author{
Rodrigo Galvão \\ Doutor e Mestre em Direito pela Universidade Federal de Santa Catarina. Professor de Direito Ad- \\ ministrativo dos Cursos de Graduação e Pós-graduação do CESUSC. Procurador Federal. Membro \\ do Instituto de Direito Administrativo de Santa Catarina
}

Sumário: Introdução - 1 A democracia como procedimentos e instituições - 2 A democracia como administração do conflito e da incerteza - 3 A democracia como expressão política do sujeito - 4 Síntese das três concepções

Palavras-chave: Democracia. Sociedade. Regime democrático. Gestão Pública. Cidadania.

\section{Introdução}

O que é a democracia na atualidade? Para além da concepção da antigüidade clássica, segundo a qual a democracia é o governo de muitos (diante da monarquia e da aristocracia), o que representa a democracia hoje? Quais são os seus traços característicos? O que a distingue dos seus opostos: os regimes totalitários e ditatoriais? Como ela pode ser ampliada? Quais os ideais e princípios que ela evoca? Que contradições internas ela possui? E a sua relação com o projeto da modernidade?

Tal reflexão se justifica na medida em que se percebe uma crise da democracia no nível mundial — não apenas no pertinente ao esvaziamento do seu modelo representativo, à hipertrofia do Executivo, à flexibilização do princípio da legalidade e à escalada da corrupção, mas no concernente a problemas mais ou menos recentes como a falta de independência da imprensa (e sua repercussão na opinião pública) numa democracia tradicionalmente paradigmática como os Estados Unidos e o refluxo de movimentos que se dizem de democracia revolucionária ou popular na América do Sul. Este estudo parece ser oportuno, também, pela proximidade com as eleições no Brasil.

Para esboçar este conceito contemporâneo, utilizam-se as ferramentas conceituais de três autores referenciais, consagrados (e não um modismo) no meio acadêmico: Bobbio, Lefort e Touraine. Não obstante se tratem de estrangeiros, são estudiosos que se reportam à realidade latino-americana e precisamente brasileira (como adiante se pontua). Possuem ampla penetração, são adotados há quase duas décadas no meio universitário brasileiro. 
Ademais, procura-se uma noção, um conteúdo mínimo universal (sem negligenciar as peculiaridades da história política brasileira). Seus conceitos não são coincidentes - mas tampouco são divergentes. Entendese que sejam complementares, na medida em que enfatizam dimensões diferentes da democracia: seus aspectos procedimentais, dialógicos, conflituosos e subjetivos.

\section{A democracia como procedimentos e instituições}

Em sua obra O Futuro da Democracia, Bobbio trata das "transformações" dos regimes ocidentais surgidos após as revoluções americana e francesa. Para o pensador, a transformação é o seu estado natural: "a democracia é dinâmica, o despotismo é estático e sempre igual a si mesmo.”"

Tal é a sua definição mínima de democracia: “(...) primariamente um conjunto de regras de procedimento para a formação de decisões coletivas, em que está prevista e facilitada a participação mais ampla possível dos interessados”; “(...) conjunto de regras (primárias ou fundamentais) que estabelece quem está autorizado a tomar as decisões coletivas e com quais procedimentos." A principal regra da democracia, segundo o autor, é a regra da maioria ${ }^{4}$ e aqueles que são chamados a decidir ou a eleger os que vão decidir devem ser postos diante de alternativas reais e em condições de escolher, através da garantia dos chamados direitos de liberdade, de opinião, de associação, etc., num Estado que exerce o poder não apenas sub lege, mas dentro de limites oriundos do reconhecimento constitucional de direitos "invioláveis" do indivíduo - o que permite, precisamente, o desenrolar do "jogo democrático".

Disto resulta, segundo Bobbio (1986, p. 20):

(...) o estado liberal é pressuposto não só histórico mas jurídico do estado democrático. Estado liberal e estado democrático são interdependentes em dois modos: na direção que vai do liberalismo à democracia, no sentido de que são necessárias certas liberdades para o exercício correto do poder democrático, e na direção oposta que vai da democracia ao liberalismo, no sentido de que é necessário o poder democrático para garantir a existência e a persistência das liberdades fundamentais.

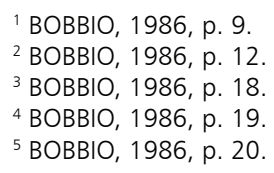

A \& C R. de Dir. Administrativo e Constitucional, Belo Horizonte, ano 6, n. 24, p. 175-187, abr./jun. 2006 
Aponta Bobbio que muito embora a democracia como método de governo esteja aberta a todos os possíveis conteúdos, ela é ao mesmo tempo muito exigente ao solicitar o respeito às instituições. ${ }^{6}$ Se o Estado despótico é o tipo ideal de quem se coloca sob o prisma do poder, o Estado democrático é o tipo ideal daquele que se coloca sob o prisma do Direito, observa. $^{7}$

Assevera o filósofo que a doutrina democrática está ligada a uma concepção individualista da sociedade (não organicista), mas não a de um indivíduo isolado e sim livremente associado, de modo a permitir a instituição de um poder não tirânico. ${ }^{8}$

Bobbio se preocupa com a ampliação dos espaços democráticos na sociedade como um todo e não apenas na política. Para uma maior extensão da democracia, após a conquista do sufrágio universal, a pergunta não deve ser "Quem vota?" e sim "Onde se vota?". 9 A democratização da sociedade, nos seus vários espaços, é o que propicia o avanço da democracia na medida em que organizações do tipo hierárquico e burocrático, como a grande empresa e a Administração Pública, resistem em tornar a sua gestão democrática - a questão já não é tanto ou apenas democratizar o poder político e sim a própria sociedade — já não se indaga do número de pessoas que votam e sim das instâncias nas quais se vota. ${ }^{10}$

Para o autor tecnocracia e democracia são antitéticas: a crença de que o governo dos técnicos é melhor que o governo exercido por qualquer cidadão é contrária ao princípio democrático. Naquela apenas o especialista é convocado a decidir e o vulgo deve ser alijado. ${ }^{11}$

Bobbio assinala como ideais necessários para a formação de cidadãos ativos de uma democracia: o da tolerância, o da não-violência, o da renovação gradual da sociedade através do livre debate de idéias e da mudança das mentalidades e o da irmandade que une todos os seres humanos num destino comum. ${ }^{12}$

Para o autor, num sistema de democracia integral, levando em conta a complexidade do Estado Moderno, deve haver uma combinação entre democracia representativa e democracia direta. ${ }^{13}$

A democracia dos modernos possui uma característica fundamental:

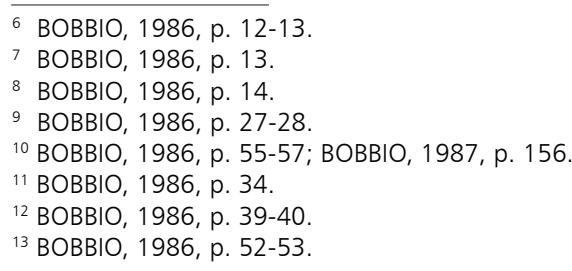

A \& C R. de Dir. Administrativo e Constitucional, Belo Horizonte, ano 6, n. 24, p. 175-187, abr./jun. 2006 
a liberdade ou, mais precisamente, a liceidade da dissenção - o consenso deve ser permanente apenas relativamente às regras da competição do "jogo democrático", salienta. ${ }^{14}$ Somente onde a dissenção é livre para se manifestar pode haver consenso real e portanto regime democrático — há uma relação necessária entre democracia e dissensão. ${ }^{15}$ Sintetiza Bobbio:

(...) a liberdade de dissentir tem necessidade de uma sociedade pluralista, uma sociedade pluralista consente maior distribuição do poder, uma maior distribuição do poder abre as portas para a democratização da sociedade civil e, enfim, a democratização da sociedade civil alarga e integra a democracia política. ${ }^{16}$

Por mais que a democracia possa sofrer mutações, Bobbio advoga que o conjunto de regras de procedimento constitucionalizadas, o sistema em seu conjunto - regras do jogo, atores, comportamentos - deve ser salvaguardado. ${ }^{17}$ Não é possível romper com todas as regras do jogo democrático, principalmente a regra das eleições periódicas, preconiza. ${ }^{18}$

Enfatiza Bobbio que a democracia é o governo do Poder Público em público — o termo "público" empregado em oposição ao "privado" e no sentido de visível, manifesto. ${ }^{19}$ Mesmo quando a Filosofia Política relegou a um segundo plano a democracia direta e passou a trabalhar com a democracia representativa, o caráter público do poder, compreendido como não secreto, como acessível ao público, permaneceu como um dos critérios fundamentais para diferenciar o estado constitucional do estado absoluto e, assim, para pontuar o nascimento e o renascimento do poder público em público, assevera. ${ }^{20}$ Outro tema profundamente relacionado com o do "poder visível”, aponta o mesmo autor, é o da descentralização compreendida como revalorização da importância política da periferia com respeito ao centro: "o poder é tanto mais visível quanto mais próximo está” (proximidade espacial entre o governante e o governado). ${ }^{21}$ Ademais, para que a opinião pública possa discutir e criticar os atos do Poder Público, os debates não apenas políticos mas todos aqueles que dizem respeito a res publica devem ser visíveis, cognocíveis, acessíveis e portanto

\footnotetext{
${ }^{14}$ BOBBIO, 1986, p. 61

15 BOBBIO, 1986, p. 63

${ }^{16} \mathrm{BOBBIO}, 1986$, p. 63-64.

${ }^{17}$ BOBBIO, 1986, p. 68-73.

18 BOBBIO, 1986, p. 82.

${ }^{19} \mathrm{BOBBIO}, 1986$, p. 84

${ }^{20} \mathrm{BOBBIO}, 1986$, p. 87.

${ }^{21}$ BOBBIO, 1986, p. 88
}

A \& C R. de Dir. Administrativo e Constitucional, Belo Horizonte, ano 6, n. 24, p. 175-187, abr.jun. 2006 
controláveis, destaca (para que possa haver democracia e a conseqüente necessidade de participação é necessário saber se alguma decisão está sendo tomada para tomar parte nela). ${ }^{22}$ Segundo Bobbio, foi Kant quem inaugurou o discurso sobre a necessidade de visibilidade do poder, vista não apenas como uma questão política mas igualmente moral: todas as ações relativas ao direito de outros cuja máxima não pode se tornar pública são injustas. ${ }^{23}$

\section{A democracia como administração do conflito e da incerteza}

Lefort não abre mão de pensar o político, onde quer que ele se encontre, suas relações com a Economia, o Direito, a Arte, etc., e pensar filosoficamente (diante da idéia de Ciência - Ciência/Sociologia política, dos dogmatismos e dos relativismos). ${ }^{24}$ Uma verdadeira interrogação sobre o político exige, segundo o autor:

(...) o abandono dos preconceitos positivistas da ciência ou da sociologia política e se vincula à inspiração da filosofia política, porém, sem se deixar submeter a essa ou aquela tradição, sem se cansar de auferir da experiência de nosso tempo - a experiência da democracia moderna e de suas ambigüidades, como a das diversas formas de totalitarismo ou de ditadura militar-burocrática $-{ }^{25}$ novos meios de compreender o que está em causa nos mais diversos registros, através da constituição de um regime (alguns diriam: sua estrutura). ${ }^{26}$

Não se pode perder, no percurso deste pensar, a perspectiva da complexidade - o que o filósofo chama de senso da complicação dos fenômenos, seu contexto histórico, os fatos novos que modificam a experiência e as concepções. ${ }^{27}$

Lefort busca reinterrogar a democracia (com as suas contradições) a partir de sua antítese, o totalitarismo - mutação de ordem simbólica e do estatuto do poder, que tem, como um de seus traços mais marcantes, a condensação entre a esfera do poder, da lei e do saber. ${ }^{28}$ Assinala:

A modernidade do totalitarismo designa-se por combinar um ideal radicalmente artificialista com um ideal radicalmente organicista. A imagem do corpo conjuga-se com a da máquina. A sociedade apresenta-se como uma comunidade cujos

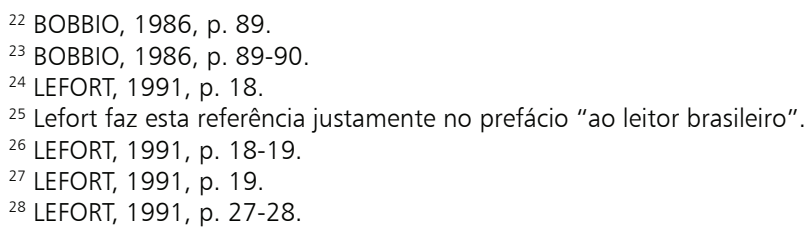

A \& C R. de Dir. Administrativo e Constitucional, Belo Horizonte, ano 6, n. 24, p. 175-187, abr./jun. 2006 
membros são rigorosamente solidários, ao mesmo tempo que se supõe em construção, pouco a pouco, perseguindo um objetivo - a criação do novo homem —, vivendo em estado de mobilização permanente. ${ }^{29}$

As características, os "sintomas" do totalitarismo, como, por exemplo, a idéia de um inimigo interno, deixam patente que a democracia é muito mais que um conjunto de instituições e procedimentos, é uma específica conformação social, que pode entrar em colapso e decantar naquela sua antítese, identifica o pensador. ${ }^{30}$ Afirma:

A partir do conteúdo do totalitarismo é que a democracia ganha um novo relevo, mostra que é impossível reduzi-la a um sistema de instituições. Aparece, por sua vez, como uma forma de sociedade; e a tarefa que se impõe é compreender no que consiste sua singularidade, e o que contém que permite o seu contrário, isto é, o advento da sociedade totalitária. ${ }^{31}$

Em face do imobilismo e da uniformidade do totalitarismo, a sociedade democrática está sempre em movimento, incorporando as novas demandas que nascem da mudança das práticas e das mentalidades, distingue o autor ${ }^{32}$ Leciona:

A democracia revela-se assim a sociedade histórica por excelência, sociedade que, por sua forma, acolhe e preserva a indeterminação, em contraste notável com o totalitarismo que, edificando-se sob o signo da criação do novo homem, na realidade agencia-se contra essa indeterminação, pretende deter a lei de sua organização e de seu desenvolvimento, e se delineia secretamente no mundo moderno enquanto sociedade sem história. ${ }^{33}$

Salienta Lefort que a democracia opera uma despersonalização, uma desincorporação revolucionária do poder, antes identificado com a figura do príncipe (o que resultava necessariamente na separação entre Estado e Sociedade). ${ }^{34}$ Diagnostica:

Incorporado no príncipe, o poder dava corpo à sociedade. (...) Tendo em vista esse modelo, designa-se o traço revolucionário e sem precedentes da democracia. O lugar do poder torna-se um lugar vazio. Inútil insistir nos pormenores do dispositivo institucional. O essencial é que impede aos governantes de se apropriarem do poder, de se incorporarem no poder. Seu exercício depende do procedimento que permite um reajuste periódico. É forjado ao

\footnotetext{
29 LEFORT, 1991, p. 28.

30 LEFORT, 1991, p. 28-29.

31 LEFORT, 1991, p. 29.

32 LEFORT, 1991, p. 30.

33 LEFORT, 1991, p. 31.

34 LEFORT, 1991, p. 31-32.
}

A \& C R. de Dir. Administrativo e Constitucional, Belo Horizonte, ano 6, n. 24, p. 175-187, abr./jun. 2006 
termo de uma competição regrada, cujas condições são preservadas de maneira permanente. Esse fenômeno implica a institucionalização do conflito. ${ }^{35}$

Esta citação bem sintetiza a concepção lefortiana: na democracia o poder não tem dono; existem regras permanentes apenas para regular um debate contínuo e incerto.

Esta desincorporação do poder, segundo o autor, traz à reboque uma desintrincação entre o âmbito do poder, da lei e do conhecimento, ${ }^{36}$ contrariamente ao totalitarismo. O saber e o direito se tornam exteriores ao poder porque este deixa de engendrar o corpo social — pontua:

(...) vemos plenamente manifestar-se a dimensão de um devir do direito, sempre na dependência de um debate sobre seu fundamento e sobre a legitimidade do que é estabelecido e do que deve ser; assim também a autonomia reconhecida do saber vai de par com um remanejamento contínuo do juízo crítico acerca dos conhecimentos e uma interrogação sobre os fundamentos da verdade. ${ }^{37}$

Direito e poder não se condensam no mesmo pólo — só há legitimidade se o poder é conforme ao direito, expõe. ${ }^{38}$

A sociedade democrática é uma sociedade sem corpo no sentido de que rejeita a representação ou a sua redução a uma totalidade orgânica, afirma. ${ }^{39}$ Sublinha Lefort que a democracia é incerteza e conflito de opiniões, debate sobre os direitos e devir:

O essencial, a meu ver, é que a democracia institui-se e se mantém pela dissolução dos marcos de referência da certeza. A democracia inaugura uma história na qual os homens estão à prova de uma indeterminação última quanto ao fundamento do Poder, da Lei e do Saber (...... ${ }^{40}$

É este mesmo conflito, esta mesma incerteza e "instabilidade" — traço distintivo da democracia - que pode, paradoxalmente, redundar no totalitarismo, quando a sociedade se vê insegura e pulverizada, alerta o pensador. Quando a insegurança dos indivíduos recrudesce, devido a crises econômicas, bélicas, estamentais e sem solução simbólica no nível do político, quando o poder se mostra dentro da sociedade e esta se vê como

\footnotetext{
35 LEFORT, 1991, p. 32.

36 LEFORT, 1991, p. 33.

${ }^{37}$ LEFORT, 1991, p. 33.

${ }^{38}$ LEFORT, 1991, p. 48.

39 LEFORT, 1991, p. 33-34.

40 LEFORT, 1991, p. 34.
}

A \& C R. de Dir. Administrativo e Constitucional, Belo Horizonte, ano 6, n. 24, p. 175-187, abr./jun. 2006 
que despedaçada, ressurge o fantasma do povo-um, do Estado liberado de toda divisão, vislumbra.

Lefort relaciona a discussão a respeito dos direitos humanos com os regimes ditatoriais e totalitários - estes não teriam sido o produto de uma concepção pervertida dos princípios daqueles, fazendo ruir todo o edifício democrático, ${ }^{42}$ na medida em que o Estado se qualificava como sabedor e supridor de todas as demandas do "povo"?

Para que surjam os novos direitos, ampliando a lista dos já existentes, é necessário que eles se inscrevam no espaço público (desfrutem de ao menos um acordo tácito por parte de uma fração importante da opinião pública) - assevera: “(...) uma das condições de êxito da reivindicação reside na convicção partilhada de que o novo direito está em conformidade com a exigência de liberdade que atestam os direitos já em vigor." ${ }^{.3}$

No que concerne ao fundamento dos direitos fundamentais, no início designados como direitos do homem, Lefort nega a concepção naturalista e a historicista (tendo em vista a evolução dos mesmos): na verdade, o que as primeiras Declarações (americana e francesa) fizeram foi reconhecer $o$ direito a ter direitos — “(...) liberando assim uma aventura cujo rumo é imprevisível."

Sintetiza o pensador:

Dito de outra maneira, a democracia convida-nos a substituir a noção de um regime regulado por leis, de um poder legítimo, pela noção de um regime fundado na legitimidade de um debate sobre o legítimo e o ilegítimo - debate necessariamente sem fiador e sem termo. Tanto a inspiração dos direitos do homem quanto a difusão dos direitos em nossa época atestam esse debate. ${ }^{45}$

Neste debate sobre o que é legítimo ou ilegítimo, esta interrogação que o direito lança sobre si próprio, não deve haver um grande juiz, nem mesmo a maioria, preconiza. ${ }^{46}$ O cerne da democracia é que haja um alargamento do espaço público no qual se propaga a discussão sobre o(s) direito(s) - de forma que todos possam participar e se manifestar, mesmo a minoria mais inexpressiva. ${ }^{47}$

\footnotetext{
${ }^{41}$ LEFORT, 1991, p. 35.

42 LEFORT, 1991, p. 38.

${ }^{43}$ LEFORT, 1991, p. 54.

${ }^{44}$ LEFORT, 1991, p. 55-56

${ }^{45}$ LEFORT, 1991, p. 57.

${ }^{46}$ LEFORT, 1991, p. 58-59.
}

A \& C R. de Dir. Administrativo e Constitucional, Belo Horizonte, ano 6, n. 24, p. 175-187, abr.jun. 2006 


\section{A democracia como expressão política do sujeito}

Aponta Touraine que a representação da democracia passou da idéia de soberania popular e de nação no século XVIII para a de um poder a serviço dos interesses da classe mais numerosa no século XIX e, na atualidade, ela se apresenta com uma feição mais defensiva, com o apelo aos temas dos direitos humanos, das minorias, dos limites traçados ao poder do Estado e ao poder econômico - o conceito, segundo o autor, distanciou-se da noção de sociedade para paulatinamente se aproximar da de Sujeito, tendendo a se tornar a sua expressão política. ${ }^{48}$

Afirma o citado autor que a história da democracia é a da separação progressiva do princípio da soberania popular e dos direitos humanos, já que a primeira tendeu a se deformar numa idéia de poder popular que deixa de lado a legalidade, arrogando-se aspirações revolucionárias e pelo fato de que os segundos muitas vezes se limitaram à defesa da propriedade. ${ }^{49}$

Por isso, segundo Touraine, não é possível hoje defender as democracias intituladas "populares" diante das democracias ditas "burguesas":

(...) a democracia só é forte quando ela submete o poder político ao respeito de direitos cada vez mais amplamente definidos, primeiramente cívicos, mas também sociais e até culturais. Se a idéia de direitos do homem encontra tanta força, é porque o objetivo principal não é mais derrubar o poder tradicional, mas proteger-se contra um poder que se identifica com a modernidade e com o povo e deixa cada vez menos espaço à contestação e às iniciativas. ${ }^{50}$

O autor contesta as chamadas democracia revolucionária e liberal: a primeira porque é separada dos atores sociais, age por eliminação, não pode conhecer o debate e a oposição entre maioria e minoria (situação que pode ser invertida); ${ }^{51}$ a segunda porque constitui um modo de gestão social que catalisa a acumulação das riquezas e concentra os poderes de decisão - aumentando assim as distâncias sociais. ${ }^{52}$ Não se pode cair no individualismo ou advogar a deterioração do Estado e do sistema político, depositando a confiança no mercado, lembra Touraine. ${ }^{53}$ Pergunta:

Somos nós incapazes de nos precaver simultaneamente contra as miragens de

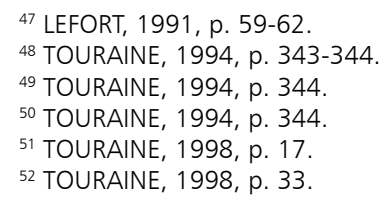

A \& C R. de Dir. Administrativo e Constitucional, Belo Horizonte, ano 6, n. 24, p. 175-187, abr.jun. 2006 
um liberalismo que aproveita mais ao centro que à periferia, e contra o perigo mortal de um poder revolucionário ou nacionalista que coloca seus interesses no lugar dos interesses do povo do qual se tornou senhor? ${ }^{54}$

As soluções liberal e revolucionária ficam sem fundamentação na medida em que se põe em questão a confiança na concepção de progresso e a democracia passa a se nutrir cada vez mais da defesa de identidades pessoais e coletivas num mundo dominado por mercados que têm ingerência cada vez maior no domínio da cultura e da personalidade — não apenas sobre os bens ou os serviços materiais. ${ }^{55}$ A democracia contradiz a idéia de progresso na medida em que se constitui em administração da diversidade e do Outro; ${ }^{56}$ recupera o próximo, o pessoal, o afetivo, o erótico, o imaginário não para se vingar ou eliminar a racionalização, mas para referir a complexidade de nossas experiências e de nossos modelos de sociedade e cultura. ${ }^{57}$ Sintetiza:

A democracia não é a meta em direção da qual marcham os que se libertam, nem pode por força maior reduzir-se ao respeito das regras do jogo político. Ela tem de ser uma força viva de construção de um mundo tão vasto quanto possível, capaz de combinar tempos passados e futuros, afinidades e diferenças, capaz, sobretudo, de recriar os espaço e as mediações políticas, as únicas que nos podem permitir deter a decomposição de um mundo levado por um turbilhão de capitais e de imagens e contra as quais se entrincheiram, numa identidade obsessiva e agressiva, os que se sentem perdedores nos mercados mundiais. A democracia não se dirige mais para um porvir radioso, mas para uma reconstrução de um espaço de vida pessoal e de mediações políticas e sociais que o protegem..$^{58}$

A democracia, leciona o pensador, deve combinar a cidadania (primeiramente a liberdade de escolhas políticas), com o respeito às identidades, às necessidades e aos direitos. Nas instituições políticas de uma democracia, entendida como regime que permite aos atores sociais ter liberdade de formação e ação, exige-se: reconhecimento e respeito aos direitos fundamentais, representatividade social dos dirigentes e da sua política e consciência de cidadania, resultante do fato de se entender pertencente a uma coletividade fundada sobre o direito. ${ }^{59}$ Segundo o autor,

\footnotetext{
53 TOURAINE, 1994, p. 345

54 TOURAINE, 1994, p. 364

55 TOURAINE, 1998, p. 44.

56 TOURAINE, 1998, p. 97.

57 TOURAINE, 1998 , p. 98.

58 TOURAINE, 1998, p. 103-104.
}

A \& C R. de Dir. Administrativo e Constitucional, Belo Horizonte, ano 6, n. 24, p. 175-187, abr./jun. 2006 
o que torna a política democrática é a possibilidade de diálogo entre as culturas.

Touraine propugna que se escolha a liberdade na sua forma negativa, no sentido de limitação do poder - ao invés de se conferir um poder absoluto a idéia de soberania popular, o que conduziria à homogeneização, transformando a sociedade em máquina e exército, anulando a criatividade pessoal e portanto a capacidade de cada indivíduo de ser sujeito de sua própria vida. $^{61}$

Rechaçada toda mitificação da coletividade política, da nação, do povo ou da república, conceitua o autor a cidadania como sendo o sentimento de responsabilidade pelo correto funcionamento das instituições que respeitam os direitos humanos e que permitem uma representação das idéias e dos interesses. ${ }^{62}$

Para o pensador, no que tange à questão da representatividade, $o$ sistema democrático é forte se os partidos políticos contribuem com respostas às questões sociais formuladas pelos próprios atores sociais e não apenas pelos próprios partidos ou pela classe dos políticos. ${ }^{63}$

Touraine aposta no Sujeito para superar o totalitarismo da razão objetiva e dar fundamento à democracia. ${ }^{64}$ Assevera:

Se a democracia é possível, é porque os conflitos sociais opõem atores que, ao mesmo tempo que se combatem, referem-se aos mesmos valores, aos quais eles procuram dar formas sociais opostas. Em lugar de se entregar a um racionalismo generalizado, tentativa para retornar ao reino da razão objetiva e estender o espírito das luzes, é preciso voltar-se para o sujeito como princípio fundador da cidadania e definir os conflitos sociais como um debate sobre o Sujeito - aposta cultural central — entre os atores sociais opostos e complementares. ${ }^{65}$

A democracia é redefinida como política do Sujeito — em oposição à concepção longamente dominante da modernidade como triunfo de uma racionalização que extingue as diferenças, que busca a padronização dos comportamentos e, simultaneamente, a construção de uma sociedade em que as operações técnicas são hierarquizadas e organizadas (racionalmente). ${ }^{66}$

\footnotetext{
59 TOURAINE, 1994, p. 345.

60 TOURAINE, 1998, p. 64.

${ }^{61}$ TOURAINE, 1994, p. 347-348.

62 TOURAINE, 1994 , p. 349

63 TOURAINE, 1994, p. 349.

64 TOURAINE, 1994 , p. 358

65 TOURAINE, 1994, p. 358.
}

$\overline{\text { A \& C R. de Dir. Administrativo e Constitucional, Belo Horizonte, ano 6, n. 24, p. 175-187, abr./jun. } 2006}$ 
Para o autor é necessário combinar a defesa das instituições democráticas e a reivindicação popular de participação: "A democratização é subjetivação da vida política., ${ }^{, 67}$

\section{Síntese das três concepções}

Muito embora as três concepções enfatizem aspectos diferentes da democracia, elas não são divergentes.

Bobbio sublinha a feição procedimental, a necessidade de respeito e manutenção das regras do "jogo democrático". Lefort destaca a faceta conflituosa, contraditória e incerta - a democracia é sempre uma obra inacabada: depende do debate contínuo e amplo sobre o legítimo e o ilegítimo, sobre a invenção de novos direitos. Mas, assim como este, aquele menciona a liberdade/liceidade da dissensão como uma nota característica do regime democrático. Touraine, por sua vez, põe no centro da sua noção de democracia o Sujeito, com a sua criatividade e inventividade, capaz de superar a razão totalitária que homogeneiza e pasteuriza, extremamente combatida por Lefort. Todos os três autores são concordes em apontar a necessidade de se franquear a maior participação possível do cidadão na gestão da coisa pública, de modo que todos, inclusive as minorias, façam-se ouvir no sistema político-administrativo — só assim a democracia se concretiza e as práticas totalitárias ou ditatoriais não têm lugar. Entende-se que tal arsenal conceitual se mantém absolutamente atual e útil para dar conta dos problemas políticos e administrativos vividos contemporaneamente, em especial no Brasil.

\section{Referências}

BOBBIO, Norberto. Estado, Governo, Sociedade: por uma Teoria Geral da Política. Tradução de Marco Aurélio Nogueira. Rio de Janeiro: Paz e Terra, 1987.

BOBBIO, Norberto. O Futuro da Democracia: uma Defesa das Regras do Jogo. Tradução de Marco Aurélio Nogueira. Rio de Janeiro: Paz e Terra, 1986.

LEFORT, Claude. Pensando o Político: Ensaios sobre Democracia, Revolução e Liberdade. Tradução de Eliana M. Souza. Rio de Janeiro: Paz e Terra, 1991.

TOURAINE, Alain. Crítica da Modernidade. 5. ed. Tradução Elia Ferreira Edel. Petrópolis: Vozes, 1994.

TOURAINE, Alain. Igualdade e Diversidade: o Sujeito Democrático. Tradução de Modesto

66 TOURAINE, 1998, p. 106

${ }^{67}$ TOURAINE, 1994, p. 365-366.

A \& C R. de Dir. Administrativo e Constitucional, Belo Horizonte, ano 6, n. 24, p. 175-187, abr./jun. 2006 
Florenzano. Bauru, SP: EDUSC, 1998.

Informação bibliográfica deste texto, conforme a NBR 6023:2002 da Associação Brasileira de Normas Técnicas (ABNT):

GALVÃO, Rodrigo. Por um conceito contemporâneo de democracia. A\&C Revista de Direito Administrativo e Constitucional, Belo Horizonte, ano 6, n. 24, p. 175-187, abr./ jun. 2006.

A \& C R. de Dir. Administrativo e Constitucional, Belo Horizonte, ano 6, n. 24, p. 175-187, abr.jun. 2006 